\title{
El concepto de 'accountability' en Facebook. Accidente ferroviario de Santiago de Compostela
}

\author{
Aurora GARCíA GonZÁLEZ \\ auroragg@uvigo.es \\ Universidad de Vigo \\ Silvia AlENDE CASTRO \\ silvia.alende@gmail.com \\ Universidad de Vigo
}

Recibido: 14 de marzo de 2014

Aceptado: 7 de octubre de 2014

\section{Resumen}

El presente trabajo analiza cómo, en una cultura de prosumidores, Facebook constituye un nuevo modelo de relación entre los medios y sus públicos. Esta investigación demuestra que la audiencia se ha lanzado al terreno de juego para exigir cuentas a los medios y que esta red social ya no es sólo una herramienta de contacto sino que se ha convertido en instrumento favorable para la rendición de cuentas. Sin embargo, por el momento se desatiende el feed-back con los usuarios y se evita el diálogo crítico necesario para que tenga lugar este proceso. Metodológicamente, este estudio se corresponde con un análisis de contenido de los comentarios generados por las informaciones publicadas por La Voz de Galicia en Facebook en relación al accidente ferroviario ocurrido en Santiago en el mes de julio.

Palabras clave: Rendición de cuentas, medios, redes sociales, diálogo crítico, usuarios.

\section{The Concept of Accountability in Facebook. Railway Accident in Santiago of Compostela}

\begin{abstract}
This project analyses as, in a prosumer culture, Facebook becomes a new way of relationship between media and public. This research shows that the audience has launched onto the playing field in order to ask for accountability to the mass media. Nowadays this social network is not only a contact tool, but it has also become a useful instrument to get accountability. However, by now the mass media heads ignore the feed-back with the users and avoid to have the necessary critical dialogue to make this process take place. Methodologically, this study corresponds with an analysis of content of the comments generated by the information published by La Voz de Galicia in relation to the railway accident happened in Santiago in July.

Keywords: Accountability, media, social network, critical dialogue, users.

\section{Referencia normalizada}

GARCÍA GONZÁLEZ, Aurora y ALENDE CASTRO, Silvia (2015): “El concepto de 'accountability' en Facebook. Accidente ferroviario de Santiago de Compostela". Estudios sobre el Mensaje Periodístico. Vol. 21, Núm. 1 (enero-junio), págs.: 317-331. Madrid, Servicio de Publicaciones de la Universidad Complutense.

Sumario: 1. Introducción y estado de la cuestión; 1.1. Rendición de cuentas. Marco teórico; 1.2. Rendición de cuentas y medios de comunicación; 1.2.1. Las redes sociales, espacio para la rendición de cuentas; 1.2.2. El caso de Facebook. 2. Material y métodos. 3. Análisis y resultados. 4. Discusión y conclusiones. 5. Referencias bibliográficas.
\end{abstract}




\section{Introducción y estado de la cuestión}

\subsection{Rendición de cuentas. Marco teórico}

La rendición de cuentas, adaptación al español del término anglosajón accountability (Antúnez, 2005: 3) se ha convertido en una exigencia ubicua en el mundo. Acuñado por Andreas Schedler (2008: 24), "su misión está en reducir las incertidumbres del poder, limitar sus arbitrariedades, prevenir y remediar sus abusos, volver predecible su ejercicio, mantenerlo dentro de ciertas normas y procedimientos preestablecidos" (Schedler, 2008: 24). Este reto lo sitúa, por tanto, como una de las ideas "indispensables" (Schedler, 2008: 5) para las democracias de hoy en día puesto que la rendición de cuentas lleva al terreno de juego a dos tipos de actores. De un lado, a los que deben rendir cuentas y, en el campo contrario, a aquellos que tienen derecho a exigirlas. En la práctica, esta propuesta teórica implica, señala su promotor (Schedler, 2008: 14), la obligación de responder a preguntas incómodas pero también la oportunidad de plantearlas. Introduce tareas de vigilancia que continúan "el proyecto de la Ilustración europea de supeditar el poder no sólo al imperio de la ley sino también al imperio de la razón" (Schedler, 2008: 14) y, como antítesis de una autoridad todopoderosa, la accountability "establece una relación de diálogo entre los actores que exigen y los que rinden cuentas. Los hace hablar a ambos, involucrándolos en un debate público" (Schedler, 2008: 14).

A modo de ejemplo de la implementación práctica de este concepto, en el caso español el ámbito económico ha visto nacer el Portal Rendición de Cuentas, una iniciativa liderada por el Tribunal de Cuentas y con la participación de la Sindicatura de Comptes de la Generalitat Valenciana, la Audiencia de Cuentas de Canarias, la Cámara de Cuentas de Madrid, la Sindicatura de Comptes de les Illes Balears, el Consejo de Cuentas de Castilla y León, la Sindicatura de Cuentas del Principado de Asturias, la Sindicatura de Cuentas de Castilla-La Mancha, la Cámara de Cuentas de Aragón y el Consello de Contas de Galicia creada para facilitar la rendición de cuentas de las distintas entidades locales y permitir el acceso a la información necesaria para conocer la gestión desarrollada en cada una de ellas. Se trata de un lugar en el que el ciudadano tiene la posibilidad de acceder a la información sobre la gestión económica de los organismos que deciden facilitar sus cuentas anuales, en una apuesta por un ejercicio de mayor transparencia con la "voluntad de informar" y "generar confianza" (Rendición de Cuentas: web). El de la administración pública es, en este sentido, uno de los entornos a los que tradicionalmente se asocia la rendición de cuentas, tanto en España como en otros países. Así por ejemplo, para el caso de Bolivia, Luis Oporto afirma:

"Es saludable, desde todo punto de vista, que las máximas autoridades de la Administración del Estado informen a la sociedad sobre los planes, programas y proyectos desarrollados [...], lo que garantiza la transparencia institucional y al mismo tiempo sacraliza el carácter público de los actos de la administración estatal, pues como no podía ser de otra manera, siendo servidores públicos, su actos tienen ese alcance por antonomasia" (Oporto, 2010: 4)

En su amplitud, la rendición de cuentas entendida en el sentido más original del término aglutina tres pilares o componentes que su impulsor teórico concreta en información, justificación y castigo, unos elementos en los que recae el verdadero "atractivo" del mismo, pues "lejos de denotar una técnica puntual para domesticar al 
poder, la rendición de cuentas abarca de manera genérica tres modos diferentes para prevenir y corregir abusos" (Schedler, 2008: 13). Sin embargo, aunque estos atributos son parte de la rendición de cuentas, su presencia conjunta no es condición absolutamente necesaria para que ésta se produzca: "al igual que el pastel de cumpleaños que reconocemos como pastel aunque le falte una rebanada, reconocemos prácticas de rendición de cuentas como tales aunque les falte una de sus tres 'rebanadas' constitutivas" (Schedler, 2008: 23).

Los autores latinoamericanos José y Margarita González Hernández concretan que este término remite a la idea de control de un sujeto sobre otro:

"Un sujeto o entidad (persona, empresa, gobierno, organización) debe rendir cuentas a otro en virtud de un acuerdo de delegación de facultades. Quien otorga facultades a otro es el mandante y quien recibe facultades en nombre de otro es el mandatario. La rendición de cuentas implica que el mandatario informe, explique y justifique las decisiones y acciones realizadas en nombre del mandante. Si la realización del encargo no satisface las expectativas establecidas por el mandante, el mandatario es susceptible de recibir algún tipo de penalización" (José y Margarita González Hernández, 2013: 75)

\subsection{Rendición de cuentas y medios de comunicación}

Como concepto convertido en una demanda omnipresente en las democracias actuales, la rendición de cuentas forma parte de algunas de las pautas de buena gestión recogidas en el Libro Blanco de la Gobernanza Europea junto a prácticas como la transparencia, la coherencia, la eficacia, la apertura a la participación y la asunción de responsabilidades, tal y como recuerdan Beatriz Catalina y Antonio García (2013) al estudiar el grado de participación ciudadana en los ayuntamientos españoles. En la actualidad, el debate sobre esta práctica se extiende también a su relación con los medios. Antúnez presenta esta vinculación: "una teoría muy en boga dice que los periodistas y los medios rinden cuentas cada día, ante el juicio del público que puede abandonarlos en cualquier momento" (2005: 2). Un supuesto que, matiza el autor, tiene parte de verdad pero también parte de falsedad: "además de comparecer cada jornada ante el público, los medios y los periodistas deben evaluar su actuación y rendir cuentas ante la gente sobre su actividad" (2005:2).

Aunque se asuma que la decisión final de consumir o no el producto informativo de una determinada empresa periodística recae, evidentemente, en el público, el engranaje entre rendición de cuentas y medios se presenta más complejo. En él, parece construirse un nuevo vínculo con el receptor, una relación "hacia lo interno, entre los distintos actores que participan de la acción cotidiana; y hacia el exterior, con los destinatarios" (Antúnez, 2005: 9). En este punto, entra en escena el papel -ya subrayado por Schedler como el corazón de la misma (2008: 15)- del diálogo crítico entre los medios de comunicación y los receptores: "no se trata de un juego de un solo tiro sino de un juego iterativo, un ir y venir de preguntas y respuestas, de argumentos y contra-argumentos" (2008: 15).

Hasta hace unos años, la posibilidad del público de establecer una conversación con los periodistas o las empresas informativas con la finalidad de exigir cuentas presentaba dificultades. No es fácil imaginar la visita, por ejemplo en la redacción de un periódico, de un nutrido grupo de lectores dispuestos, a diario, a pedir datos, preguntar 
porqués y evaluar, cara a cara, decisiones y contenidos del propio diario. Sin embargo, en la actualidad, este proceso se ha vuelto más sencillo, explica Antúnez:

"Cada día, las posibilidades que brinda el desarrollo de las nuevas tecnologías de la información y las comunicaciones hacen más accesibles los instrumentos para que más personas puedan expresar sus puntos de vista o sus reflexiones críticas sobre los acontecimientos y aún sobre la acción de las instituciones y los hombres y mujeres que las orientan" (Antúnez, 2005: 11)

Precisamente, la relación entre gobierno y ciudadanía en una era marcada por el influjo de la red lleva a José Sixto (2013: 59) a asegurar que "en este cambio evolutivo, tienen mucho que ver la innovación tecnológica y las nuevas formas de comunicación [...] que permiten hacer públicas -y compartidas- las preocupaciones y las ansias que hasta ahora eran celosamente privadas". Según los datos facilitados por el Observatorio Nacional de las Telecomunicaciones y de la Sociedad de la Información (ONTSI) en la XL Oleada del panel de hogares 'Las TIC en los hogares españoles', en el tercer trimestre de 2012, el 66,9\% de los hogares dispone de acceso a Internet, cifra que supone un alza de 6,3 puntos porcentuales más con respecto al mismo trimestre del año anterior.

Esta mayor presencia de Internet en los hogares españoles ha transformado también la forma de relacionarnos y acceder a los contenidos. Así, en el caso concreto del consumo de periódicos, los resultados de la última encuesta Navegantes en la Red de la Asociación para la Investigación de los Medios de Comunicación (AIMC) indican que los internautas que leen únicamente la versión electrónica suben algo más de cinco puntos respecto a 2011 situándose en el 37,7\%, mientras que descienden 1,4 puntos los que leen exclusivamente la versión en papel, con casi el $8 \%$. Por tanto, Internet, las distintas modalidades de comunicación online o las redes sociales pueden entenderse ya como una revolución en la forma de comprender las relaciones actuales entre los medios y su público. Así lo siente Gustavo Antúnez, que va más allá y concreta que "sin perjuicio de la brecha digital [...], hay cada vez más instrumentos que nos permiten expresar nuestra opinión", lo cual constituye "un avance muy importante, porque permite en muchos casos cerrar el circuito de la comunicación, permitiendo el feed-back" (2005: 11).

De este modo, si antes de la aparición de estos nuevos modelos comunicativos el mensaje se emitía y llegaba intacto al receptor, ahora a las múltiples fuentes emisoras se suma la capacidad de los receptores para actuar como intermediarios. Es un camino que, a día de hoy, se corresponde ya con la era de las aplicaciones en el móvil como modo ampliamente extendido de acceso a los contenidos mediáticos, una fase que para Costa Sánchez representa ya la tercera etapa en la evolución del periodismo en la pequeña pantalla, tras pasar por un primer momento de adaptación al dispositivo (información en formato SMS o MMS y de pago) y de un segundo instante, mediante una "dificultosa navegación por una versión web del diario con textos cortos e imágenes en baja calidad" (2013: 9).

En este proceso del tránsito hacia la comunicación dirigida al individuo digital, las empresas periodísticas y el público han afrontado multitud de modificaciones en el 
modo de operar, acceder y recibir la información. La profesora española Tatiana Millán Paredes explica al respecto que "cualquier cambio en los medios de comunicación viene a significar un cambio en la propia realidad comunicada" (2004: 84). Así, estas alteraciones pueden comprenderse como una nueva aportación a la consolidación y el fortalecimiento de la democracia, donde Internet se presenta como uno de los recursos de comunicación con mayor potencial.

\subsubsection{Las redes sociales, espacio para la rendición de cuentas}

Son ya numerosos los análisis centrados en la comunicación a través de las redes sociales, que pueden definirse como un servicio llegado de la mano de Internet que permite a cualquier cibernauta construirse un perfil dentro de un sistema gestionado por un tercero, compartiendo relaciones con otros usuarios, tal y como sostienen como Bernal y Angulo $(2013,25)$. Para autores como los ahora mencionados, su crecimiento y extensión permiten hablar ya de estas redes como un "nuevo entorno de socialización" (2013: 26), especialmente entre la población de menor edad, tal y como se pone de manifiesto en distintos estudios internacionales ${ }^{1}$.

La comunicación es el motivo descrito por buena parte de los usuarios de las redes sociales para abrirse una cuenta (Bernal y Angulo, 2013: 26). Dada la progresión sufrida en los últimos años por este tipo de plataformas de comunicación caracterizadas, para Lucía Tello, por la dispersión de los usuarios y la constante reforma tecnológica (2013: 208)- las aproximaciones realizadas en torno a su funcionamiento presentan ya un salto cualitativo. Con base en aportaciones internacionales ${ }^{2}$, la autora eslovena Karmen Erjavec describe las redes como instrumentos con ventajas e inconvenientes. En el primer caso, las sitúa como una forma más fácil, rápida y barata de comunicación. En el extremo opuesto, cita la impersonalidad que puede llevar a la alienación o el aislamiento social (2013: 118).

El contacto entre personas se ha digitalizado, de modo que a diario contactamos con más gente (unas 23 personas de media) a través de las redes sociales que de forma personal (16), según la $13^{\mathrm{a}}$ y última edición del informe anual La Sociedad de la Información en España. Estos instrumentos sin duda destacan sobre los demás (blogs, microblogs o wikis) tanto por sus posibilidades comunicativas como por marcar un antes y un después en la historia de la comunicación, presentando unas circunstancias en las que, apunta Sixto, "parece que hemos retrocedido dos milenios en el tiempo y que hay una necesidad colectiva de volver a tomar las decisiones en el ágora" (2013: 59).

En el caso concreto de los medios, esto ha supuesto un cambio trascendental que ofrece nuevas posibilidades pero esconde también exigencias hasta ahora desconocidas. Se trata de una forma social que, en el camino de una sociedad transformada en tecnosociedad, impone otras formas de comprar y vender, de producir o de distribuir pero también de hacer periodismo (Sáez, 2013: 15), lo que ha obligado a los medios a "replantearse cómo relacionarse con unos usuarios que demandan un papel mucho

${ }^{1}$ Cfr. Chew \& al., 2011; Mazur \& Richards, 2011; \& al., Mikami 2010; Gross \& al., 2002, Garmendia \& al., 2011.

2 Cfr. Ellison \& al., 2007. 
más activo y un mayor protagonismo", aseguran Díaz-Campo y Segado-Boj (2013: 211). Así lo afirma también Aurora García al señalar que "las redes sociales han contribuido a crear proximidad" (2013: 256).

Movimientos ciudadanos como el de Democracia Real ${ }^{3}$ o el $15-\mathrm{M}^{4}$ demostraron el poder de participación y conexión de las redes sociales. Su volumen de datos afectó también a los medios de comunicación, que se vieron abocados a asumir cambios en sus rutinas de producción informativa. Así, apunta Sixto, "a pesar de que algunas voces, quizás bastantes, criticaron el uso desmesurado y descontrolado de las redes sociales ligado a la incapacidad para discernir entre el rumor, lo real y la falsedad, lo que es innegable es que las redes sociales a día de hoy son ya una parte imprescindible del panorama mediático" (2013: 64). Todo ello constata, señalan Castillo, García y Smolak, un poder doble: "por un lado de los medios sociales online en difusión de las causas e ideas sociales. [...] Por otro lado nos enseña el poder de los movimientos sociales [...] y del nuevo usuario socialmente consciente y hiperconectado" (2013: 88-89).

En definitiva, además de ser un arma poderosa para la convocatoria y la movilización, no resulta equivocado afirmar, hoy por hoy, que estos instrumentos -que suman ya millones de usuarios en todo el mundo (Sixto, 2013: 65)- alteran la agenda de los medios y su producción informativa, narrando la historia en directo y haciendo que, tanto desde fuera como desde dentro de las propias empresas mediáticas, la información no pueda seguir entendiéndose del mismo modo. Con claras consecuencias en el periodismo, este fenómeno conlleva para Meléndez y Cuartero "una dimensión de la realidad directamente vinculada a los medios pero, al mismo tiempo, resulta un espacio en el cual emergen [...] otras dinámicas comunicativas" (2013: 178).

\subsubsection{El caso de Facebook}

En España, las redes sociales se han universalizado y, en la actualidad, un $93 \%$ de los internautas cuanta con, al menos, una cuenta activa. Así se desprende de los resultados de la $5^{\text {a }}$ Oleada del Observatorio de Redes Sociales, realizada por The Cocktail Analysis en colaboración con la agencia Zenith. En la era de la convergencia, sostienen Videla y Piñeiro -citando a Jenkins- "la penetración alcanzada por Internet y la democratización de determinadas Tecnologías de la Información y la Comunicación ha propiciado la creación de una red mundial de conexiones" (2013: 85). El estudio del fenómeno ofrece varias conclusiones importantes. Por una parte, la desaceleración de estas herramientas debido al auge de la mensajería instantánea, de modo que un $17 \%$ de los internautas con cuenta activa en Facebook y el 64\% de los de Tuenti declaran utilizar cada vez menos estas redes. Pero, en el extremo opuesto, destaca la notable presencia de las redes sociales en el día a día de los usuarios españoles: Facebook sigue siendo la red líder absoluta ( $83 \%$ de los entrevistados declaran tener una cuenta activa) seguida de Twitter (42\%), Tuenti (27\%), Google+ (27\%), LinkedIn (18\%), Instagram (12\%) y otras como Flickr, Foursquare, Tumblr, Pinterest o Ask.fm.

3 Creado por el abogado Fabio Gándara, su ideario ponía en duda el sistema capitalista.

4 El 15-M se presentó como una protesta contra el mal uso que los políticos están haciendo de la democracia. 
De todas ellas, Facebook se presenta como plataforma por antonomasia. Aquellos que tienen cuenta en esta red y la utilizan explican que, de los motivos que los llevan a usarla, el más frecuente es la facilidad para mantener el contacto con el círculo social cercano, localizar a amigos o hacer planes. Informarse, expresarse y mantener conexión con el círculo social lejano son otras de las razones que llevan a los españoles a decantarse por esta plataforma, según The Coktail Analysis. El perfil más habitual del usuario español en Facebook tiene, de media, 31 años, aspecto que se mantiene invariable desde el 2011. Además, apuntan García, López de Ayala y Catalina que "son aquellos que hacen un uso más intensivo de las redes sociales quienes realizan con más frecuencia actividades en la Red" (2013: 202).

Ver las actualizaciones de los contactos (73\%) y compartir fotos (42\%) suponen el principal tipo de uso de Facebook. De entre todas sus características, destaca su empleo preferentemente como vehículo de promoción de contenidos y el perfil más conversacional de Twitter (Díaz-Campo y Segado-Boj, 2013: 212). Por tanto, aunque Facebook se sigue situando como referente absoluto, según este estudio se constatan, sin embargo, ciertos indicadores de distanciamiento que The Cocktail Analysis concreta en la configuración de su imagen como imagen de las redes sociales (para lo bueno y para lo malo) o los problemas de privacidad que cristalizan en ella.

Facebook se presenta, por tanto, como una herramienta de y para la comunicación. En ella, al igual que ocurre en otras plataformas, explica Inmaculada Berlanga, se produce una aproximación entre el novedoso discurso digital y la Retórica clásica. Tomando como referencia a Tomás Albaladejo, la autora afirma que "la comunicación discursiva persuasiva que se apoya en la Retórica ha encontrado en la sociedad digital $[\ldots]$ unas posibilidades [...] como nunca antes había habido. La comunicación retórica ha llegado a tener, gracias a las nuevas tecnologías, unas altísimas posibilidades en cuanto a número y conjuntos de receptores" (2013: 51-52). Discursivamente, Facebook acerca las cabeceras periodísticas a sus usuarios, posibilitando la relación entre ambos y la comunicación de tú a tú. A continuación, veremos si las herramientas de esta red social se están aprovechando para establecer el diálogo crítico con el público al que Schedler aludía como el corazón de la accountability o si, por el momento, ésta no representa todavía una apuesta de los medios en una era de prosumidores ${ }^{5}$ en la que los usuarios activos ya no solo acceden y consumen contenidos, sino que también los producen (Videla y Piñeiro, 2013: 83) y difunden y en la que la gran novedad radica en una tecnología no de la reproducción sino de la producción (Millán, 2006: 172).

\section{Material y métodos}

El objetivo de esta investigación consiste en el estudio del concepto de accountability periodística en Facebook. En concreto, este trabajo trata de conocer si, efectivamente, esta red social sirve de canal para que se produzca el doble juego al que aludía Schedler como rendición de cuentas, es decir, si posibilita que aquellos que piden cuentas puedan plantear preguntas y, por otro lado, si los actores a los que éstas se di-

5 Del inglés prosumer, es un término acuñado por Toffler (1980). Hace referencia a un individuo que asume roles de productor y consumidor a la vez. 
rigen emiten algún tipo de respuesta que implique la materialización de este proceso. De modo concreto, se plantean las siguientes hipótesis:

H1: Los medios españoles no rinden cuentas ante los usuarios de sus redes sociales. Se limitan a publicar información pero desatienden el feed-back con su audiencia.

$\mathrm{H} 2$ : Facebook constituye, tecnológicamente, un canal que posibilita el proceso de rendición de cuentas.

H3: Los usuarios ya están exigiendo cuentas a través de esta plataforma.

H4: En una era de prosumidores, todavía no se produce el diálogo crítico entre emisor y receptor que constituye la base de la accountability.

Para tratar de refutar o comprobar estas afirmaciones, se ha tomado como referencia el perfil oficial del periódico gallego La Voz de Galicia en esta red social y, en concreto, las publicaciones realizadas por el diario en relación al accidente ferroviario registrado en Santiago el 24 de julio 6 . Metodológicamente, se ha procedido al análisis cuantitativo y cualitativo de los comentarios recibidos por los distintos post de esta cabecera sobre este suceso. En relación al marco temporal, se han tenido en cuenta las publicaciones emitidas durante una semana, en concreto entre el propio día del accidente -el 24 de julio- y el 31 de julio. Así, por cada comentario perteneciente a estas publicaciones se ha valorado, en primer lugar, si proviene de la empresa o de los usuarios. En el primer caso, una segunda subcategoría trata de evaluar si ese mensaje añade información, responde a un usuario o constituye una defensa ante una réplica anterior.

Por su parte, de los comentarios de los usuarios se tiene en cuenta, inicialmente, si no contiene referencias al tratamiento de la información en el que se encuentra inserto o si, por el contrario, sí se refiere a ese enfoque periodístico. En aquellos casos en los que el comentario se refiere al tratamiento informativo, se valora si el usuario muestra, a través de él, acuerdo o desacuerdo. De los comentarios disconformes, se analiza a continuación el tipo de sentimiento expresado. Así, se estudia si pide explicaciones por el tratamiento noticioso, exige cambios en el mismo, propone sugerencias en este sentido, muestra indignación ante el enfoque o muestra desacuerdo pero manifiesta comprender la necesidad de la publicación así realizada. A continuación, se recoge esta ficha de análisis:

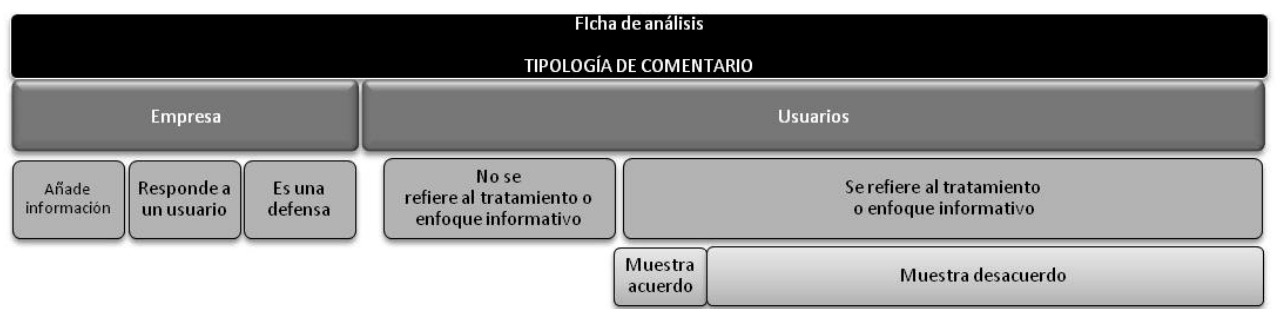

${ }^{6}$ El siniestro tuvo lugar en la curva de A Grandeira, en la parroquia de Angrois y a unos tres kilómetros de distancia de la estación de Santiago. Un tren proveniente de Madrid y con destino final en Ferrol ocupado por más de doscientos pasajeros descarriló minutos antes de las 21.00 horas, causando la muerte a, al menos, 79 personas y provocando multitud de heridos. 


\begin{tabular}{|c|c|c|c|c|}
\hline \begin{tabular}{|c|} 
Pide \\
explicaciones \\
porel \\
tratamiento \\
informativo
\end{tabular} & $\begin{array}{c}\text { Exige } \\
\text { cambios en } \\
\text { el mismo }\end{array}$ & $\begin{array}{c}\text { Propone } \\
\text { sugerencias }\end{array}$ & $\begin{array}{c}\text { Muestra } \\
\text { indignación }\end{array}$ & $\begin{array}{l}\text { Matizasu } \\
\text { comprensión }\end{array}$ \\
\hline
\end{tabular}

Ilustración 1. Ficha de análisis aplicada a cada comentario. Elaboración propia.

La selección de este caso se deriva, además de su cercanía en el tiempo, del impacto que el mismo tuvo en la sociedad española y, en concreto, en la gallega. Se ha optado por analizar el perfil oficial en Facebook de La Voz de Galicia por tratarse de uno de los diarios de referencia en la comunidad, teniendo en cuenta que uno de los intereses de este estudio pasa por conocer la reacción generalizada de la audiencia. Asimismo, se han descartado otras opciones como las cabeceras barajadas también en un primer momentoFaro de Vigo o El Correo Gallego debido a la imposibilidad, a mediados de octubre, de recuperar gran parte de las publicaciones realizadas por ambos periódicos. Los propósitos de este trabajo son evaluar si el público se pronunció o no sobre el tratamiento de la información, cuantificando en qué medida pudo exigir cuentas pero poniendo también el punto de de mira en el aspecto cualitativo, es decir, tratando de conocer, si lo hacían, qué demandaron los usuarios al medio y si este respondió.

\section{Análisis y resultados}

En el momento de recogida de los datos de este estudio, el 14 de octubre y, por tanto, menos de tres meses después de haberse producido el accidente ferroviario de Santiago, es posible recuperar once piezas informativas publicadas por el periódico gallego La Voz de Galicia en su página oficial de Facebook. En conjunto, estas publicaciones generaron 13.243 me gusta y fueron compartidas en 10.024 ocasiones. Asimismo, recibieron 1.449 comentarios, una media de 131 por pieza informativa. En relación al objeto de estudio de este análisis, los comentarios recibidos, cabe señalar que todos ellos fueron emitidos por los receptores de la información, no contabilizándose ninguna respuesta de la cabecera periodística, a pesar de las solicitudes directas de los usuarios en este sentido.

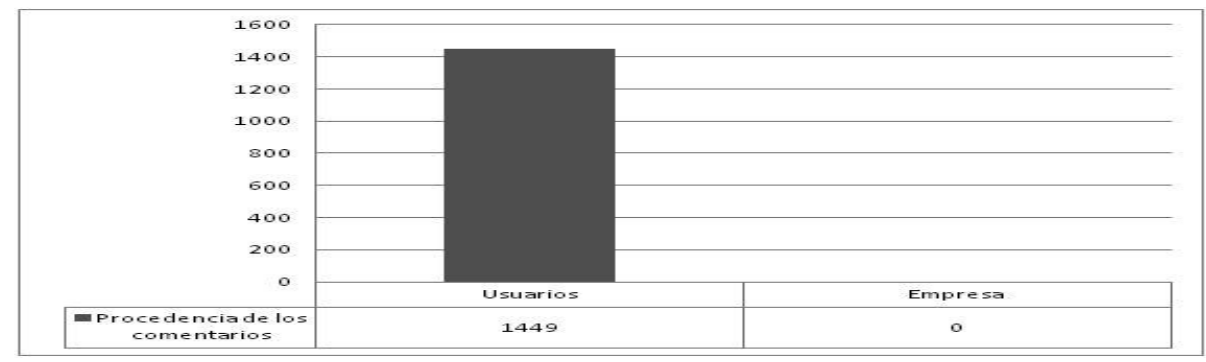

Tabla 1. Procedencia de los comentarios. Elaboración propia.

De los 1.449 comentarios enviados por los usuarios, 1.250 no se referían a la información mientras que otros 199 sí mostraban juicios sobre la misma. Estos datos suponen un $86 \%$ de comentarios no referentes a la información y un $14 \%$ sí referentes. Por su parte, de los 199 comentarios recibidos por estas piezas que sí contenían refe- 
rencias a la propia información, 36 expresaban acuerdo hacia la misma (un 18\%) mientras que otros 163 (un 82\%) mostraban estar en desacuerdo con el tratamiento realizado por la cabecera. En el caso concreto del tipo de desacuerdo contenido en estos 163 comentarios disconformes, la indignación -presente en 109 ocasiones- es el sentimiento más común entre aquellos usuarios que decidieron expresarse en contra del enfoque de alguna de estas piezas. Porcentualmente, la cifra supone que un $67 \%$ de los comentarios disconformes y más de la mitad -un 55\%- de todas las respuestas vinculadas a estas publicaciones mostraban este tipo de irritación a la información. Por frecuencia, la siguiente percepción disconforme más habitual hacia estas piezas hace referencia a la demanda de cambios en el modo de orientar la información, una reacción detectada en el $18 \%$ de los comentarios en desacuerdo y en un $15 \%$ de todas las respuestas relativas a las noticias o vídeos compartidos por La Voz de Galicia sobre la tragedia del tren.

De este análisis se desprende también que hubo receptores que, si bien mostraban su desacuerdo ante lo que en ese momento leían o visionaban, también manifestaban su comprensión con el modo de actuar de este medio. En concreto, esta situación fue diagnosticada en 11 ocasiones, es decir, en un 7\% de los comentarios disconformes y en un 5\% de todas las respuestas centradas en la emisión de opinión sobre el tratamiento de los datos. La sugerencia de nuevos enfoques a la cabecera coruñesa centró otros 9 comentarios, cifra que representa un $5 \%$ y un $4 \%$, respectivamente, si se compara con el total de réplicas disconformes o con el número de respuestas referentes al tratamiento informativo. Finalmente, cinco comentarios reflejaron una crítica más acuciante hacía el enfoque ofrecido en estas piezas, llegando a exigir explicaciones directas al medio en este sentido. En términos porcentuales, la cifra implica un 3\% si se compara con los comentarios disconformes y algo más de un $2,5 \%$ en caso de que la valoración se realice respecto al total de respuestas referentes a la información.

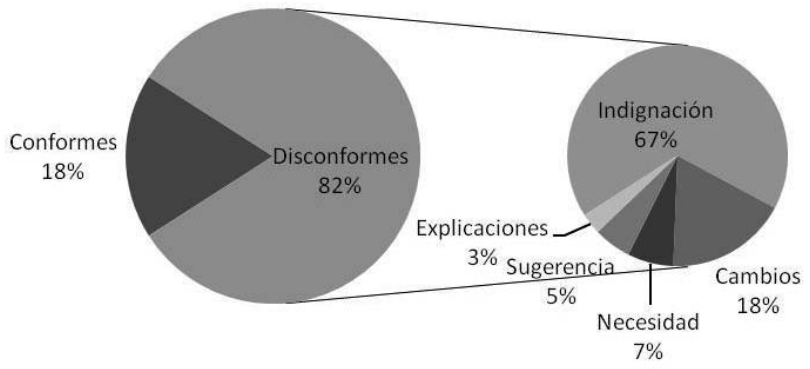

Tabla 2. Tipología de comentarios referentes al tratamiento informativo. Elaboración propia.

Cualitativamente, este análisis posibilita también el diagnóstico de los motivos por los que los usuarios decidieron mostrar su parecer ante la información mencionada. En este sentido, la principal razón de apoyo a la información fue la necesidad de conocer el alcance real de la tragedia. Por su parte, en el caso de los comentarios disconformes, los usuarios de la página de La Voz de Galicia en Facebook aludieron a diversas razones, entre ellas el morbo que, a su parecer, transmitían las publicaciones, la dureza 
de las imágenes empleadas, la falta de ética, la búsqueda del fin económico antes de cualquier otro objetivo o la ausencia de respeto. Por ello, los receptores de estas informaciones no dudaron en solicitar al periódico que esperase los resultados de la investigación antes de aventurar hipótesis y que ofreciese información de utilidad, evitando la "carnaza" y los contenidos "amarillistas" y llegando a exigir a la dirección de la empresa una revisión de la línea editorial. Ya en las jornadas más lejanas al registro del accidente ferroviario, los receptores hicieron más frecuente la petición de información sobre otras temáticas.

\section{Discusión y conclusiones}

Los resultados de este estudio permiten confirmar la veracidad de las cuatro hipótesis planteadas y cumplir así el objetivo marcado con esta investigación: analizar el novedoso y poco estudiado todavía- empleo de Facebook como instrumento de rendición de cuentas. De este modo, se pudo conocer cómo La Voz de Galicia no apuesta todavía por rendir cuentas ante sus usuarios en esta red social pese a que esta plataforma constituye un canal que tecnológicamente así lo posibilita. Como se pudo comprobar, actualmente los receptores digitales ya comentan con asiduidad las piezas informativas que el medio comparte en esta red social y, con frecuencia, emplean este canal para valorar el tratamiento o enfoque informativo, una cuestión que antes de la generalización de estos entornos digitales presentaba mayores complicaciones de materialización.

Es decir, los usuarios se han lanzado al terreno de juego y están ya exigiendo cuentas a la cabecera, solicitando información, justificaciones e incluso anunciando acciones de castigo como la advertencia de dejar de consumir sus contenidos. En este caso, en 163 ocasiones los lectores decidieron redactar un comentario disconforme con el tratamiento informativo al que acababan de tener acceso. Sin embargo, la cabecera gallega no se pronunció en ningún momento, a pesar de recibir requerimientos expresos en este sentido y pese a que cuatro de cada cinco comentarios relativos al tratamiento informativo se mostraron contrarios al mismo. Tampoco lo hizo en el caso de los 36 comentarios que manifestaron acuerdo con lo publicado.

En estas circunstancias, puede afirmarse que la presencia de este medio en Facebook se limita a la promoción de información procedente de su web. Se comprueba así que hasta el momento la cabecera ha desatendido el feed-back con su audiencia que posibilitan estas plataformas, evitando el diálogo necesario para que tenga lugar la rendición de cuentas y el rol de orientador que socialmente se le demanda. Por tanto, a partir de este estudio puede entenderse que la existencia de la herramienta no significa que los medios estén comprendiendo todavía la necesidad de rendir cuentas, siendo transparentes ante su audiencia y argumentando sus decisiones, aún cuando como sucedió en este caso concreto- el alegato del público se dirija a la dirección de las propias cabeceras.

En esta tesitura y pese a encontrarnos inmersos en una cultura de prosumidores y escenarios participativos en la que la extensión y empleo de las innovaciones es constante en los dos bandos -el de los medios y el de las audiencias-, la comunicación sigue presentándose, en el caso de La Voz de Galicia y sus públicos, de modo unidi- 
reccional. Hay participación entre la audiencia y efectivamente los usuarios tienen, hoy en día, recursos y herramientas que permiten acercarse a la cabecera pero, sin embargo, no hay todavía interactuación discursiva real entre el medio o los periodistas y sus lectores.

Así, puede afirmarse que el sistema comunicativo sigue todavía el dictado del modelo tradicional de pilotaje, conformado por la selección y control de los contenidos a pesar de no ser ésta la modalidad esperada en el actual entorno colaborativo, abierto y participativo Se cae así en una contrariedad histórica, puesto que si averiguar la opinión del público -el efecto de la comunicación en el receptor- fue siempre una de las prioridades del entramado mediático, hoy en día -cuando puede conocerse con mayor facilidad- no se está atendiendo o, al menos, no se está reconociendo que se tenga en cuenta esta opinión de los lectores.

De este modo y hasta que la rendición de cuentas se cuele entre las prioridades de los medios como proceso democrático y responsable hacia su audiencia, vuelven a estar de actualidad las palabras pronunciadas por Schedler hace ya más de seis años según las cuales debemos seguir insistiendo, preguntando, cuestionando y exigiendo, puesto que la rendición de cuentas no es un derecho de petición sino un derecho a la crítica y al diálogo. A la vista de los resultados de esta investigación, el público parece dispuesto a seguir apelando a una responsabilidad social intrínseca que no está escrita pero que es parte del encargo social que se deposita en el sistema global de comunicación y en el que Internet, como medio pensado para la guerra, ha de convertirse también en un artefacto para buenos usos democráticos, críticos y justos.

\section{Referencias bibliográficas}

AIMC (2013): Navegantes en la Red - Encuesta AIMC a usuarios de Internet $15^{a}$. Madrid, Sersa. (http://download.aimc.es/aimc/4uT43Wk/macro2012.pdf) (25-102013).

ANTÚNEZ, Gustavo (2005): “Accountability. Rendición de cuentas”, en Centro de Competencia en Comunicación para América Latina: http://www.fesmedia-latinamerica.org/uploads/media/Accountability.pdf) (28-10-2013.

BERLANGA, Inmaculada (2013): "Retórica clásica y redes on line: dos realidades convergentes y análogas. Perspectivas y prospectivas de 9 expertos en Comunicación". Icono 14, volumen 11 (1), pp. 45-70. http://dx.doi.org/10.7195/ri14.v11i1 .548) (28-10-2013.

BERNAL, César y ANGULO, Félix (2013): "Interacciones de los jóvenes andaluces en las redes sociales". Comunicar, 40, pp. 25-30. http://dx.doi.org/10.3916/C402013-02-02 (27-10-2013).

CASTILLO, Antonio; GARCÍA, Damián; y SMOLAK, Emilia (2013): "Movimientos sociales y estrategias de comunicación. El caso del 15-M y de Occupy Wall Street". Estudios sobre el mensaje periodístico. Vol. 19, (1), pp. 71-89. Madrid, Servicio de Publicaciones de la Editorial Complutense. http://dx.doi.org/10.5209 /rev_ESMP.2013.v19.n1.42508 (26-10-2013). 
CATALINA, Beatriz y GARCÍA, Antonio (2013): "Herramientas interactivas y participación ciudadana en los ayuntamientos españoles". Ámbitos-Revista Internacional de Comunicación, $\mathrm{n}^{\mathrm{o}}$ 22. http://ambitoscomunicacion.com/2013 /herramientas-interactivas-y-participacion-ciudadana-en-los-ayuntamientos-espanoles/ (15/01/2014).

CHEW, Han Ei; LAROSE, Robert; VELASQUEZ, Alcides; STEINFIELD, Charles (2011): "The Use of Online Social Networking by Rural Youth and its Effects on Community Attachment". Information, Communication \& Society, 14 (5), pp. 726747. http://dx.doi.org/10.1080/1369118X.2010.539243 (28-10-2013).

COMISIÓN EUROPEA (2011): La gobernanza europea - Un Libro Blanco. [COM (2001) 428 final - Diario Oficial C 287 de 12/10/2001]

COSTA, Carmen (2013):"“Prensa en el Smartphone. Modelos aplicados en los diarios españoles y necesidades de desarrollo". Icono 14, volumen 11 (2), pp. 07-30. http://dx.doi.org/10.7195/ri14.v11i2.591 (29-10-2013).

DÍAZ-CAMPO, Jesús y SEGADO-BOJ, Francisco (2013): "La radio en Facebook: análisis de los perfiles de las principales emisoras y programas radiofónicos en España". Icono 14, volumen 11 (2), pp. 209-228. http://dx.doi.org/10.7195 /ri14.v11i2.517 (27-10-2013).

ELLISON, Nicole B.; STEINFIELD, Charles; \& LAMPE, Cliff (2007): "The Benefits of Facebook 'friends': Social Capital in College Students' Use of Online Social Network Sites". Journal of Computer-Mediated Communication, 12, 4, pp. 1143-1168. (http://dx.doi.org/10.1111/j.1083-6101.2007.00367) (24-10-2013).

ERJAVEC, Karmen (2013): “Aprendizaje informal a través de Facebook entre alumnos eslovenos". Comunicar, 41, pp. 117-126. http://dx.doi.org/10.3916/C41-201311 (28-10-2013).

FUNDACIÓN TELEFÓNICA (2013): La Sociedad de la Información en España 2012. Barcelona, Ariel. http://elibros.fundacion.telefonica.com/sie12/aplicacion_sie/ParteA/pdf/SIE_2012.pdf (20-10-2013).

GARCÍA, Antonio; LÓPEZ DE AYALA, Mari Cruz; y CATALINA, Beatriz (2013): "Hábitos de uso en Internet y en las redes sociales de los adolescentes españoles". Comunicar, 41, pp. 195-204. http://dx.doi.org/10.3916/C41-2013-19 (29-10-2013).

GARCÍA GONZÁLEZ, Aurora (2013): "De la radio interactiva a la radio transmedia: nuevas perspectivas para los profesionales del medio". Icono 14, volumen 11 (2), pp. 251-267. http://dx.doi.org/ 10.7195/ri14.v11i2.567 (27-10-2013).

GARMENDIA, Maialen; GARITAONANDIA, Carmelo; MARTÍNEZ, Gemma; et al (2011): Riesgos y seguridad en Internet: Los menores españoles en el contexto europeo. Bilbao, Universidad del País Vasco, EU Kids Online. http://www.lse.ac.uk /media@1se/research/EUKidsOnline/EU\%20Kids\%20II\%20\%282009-11\%29/National\%20reports/Spanish\%20report.pdf (24-10-2013).

GONZÁLEZ HERNÁNDEZ, José y GONZÁLEZ HERNÁNDEZ, Margarita (2013): "Rol del agente y estructuras de rendición de cuentas en programas sociales me- 
xicanos. El caso del programa 3x1 en Zacatecas". Revista chilena de derecho y ciencia política, $\mathrm{n}^{\circ} 2$, vol.4, pp. 73-101. http://dialnet.unirioja.es/servlet/articulo? codigo $=4346298(17 / 01 / 2014)$.

GROSS, Elisheva; JUVONEN, Jaana; \& GABLE, Shelly (2002): "Internet Use and Well-being in Adolescence". Journal of Social Issues, 58 (1), pp. 75-90. http://dx.doi.org/10.1111/1540-4560.00249 (28-10-2013). http://www.rendiciondecuentas.es/es/index.html (20/01/2014)

LLISTAR, David (2011): "A la izquierda de Internet: las redes ciudadanas y las nuevas formas de organización civil". Comunicar, 16, 2011, pp. 63-68. http://www.revistacomunicar.com/index.php?contenido $=$ detalles \&numero $=16 \&$ articulo $=16-200$ 1-10\&mostrar=resumen\#resumen (28-10-2013).

MAZUR, Elizabeth y RICHARDS, Lacey (2011): “Adolescents and Emerging Adults' Social Networking Online: Homophily or Diversity?". Journal of Applied Developmental Psychology, 32, pp. 180-188. http://dx.doi.org/10.1016/j.appdev.2011.03.001 (28-10-2013).

MELÉNDEZ, Natalia y CUARTERO, Antonio (2013): "La aparición de las redes sociales como contenido informativo en los medios tradicionales: análisis comparativo en dos diarios españoles de referencia (2006-2010)". Estudios sobre el mensaje periodístico, vol. 19, (1), Madrid, Servicio de Publicaciones de la Editorial Complutense, pp. 177-189. http://dx.doi.org/10.5209/rev_ESMP.2013.v19.n1.42515 (25-10-2013).

MIKAMI, Amori Yee; SZWEDO, David; ALLEN, Joseph; et al (2010): “Adolescent Peer Relationships and Behavior Problems Predict Young Adults Communication on Social Networking Websites". Developmental Psychology, 46 (1), pp. 46-56. http://dx.doi.org/10.1037/a0017420 (28-10-2013).

MILLÁN, Tatiana (2006): "La digitalización de la realidad en las nuevas generaciones del siglo XXI". Comunicar, 26, pp. 171-175. http://www.revistacomunicar.com/index.php?contenido=detalles\&numero=26\&articulo=26-2006-26\&mostrar=resumen\#resumen (24-10-2013).

MILLÁN, Tatiana (2004): "De la comunicación de masas al individuo digital". Comunicar, 23, pp. 83-87. http://www.revistacomunicar.com/index.php?contenido $=$ detalles $\&$ numero $=23 \&$ articulo $=23-2004-14 \&$ mostrar $=$ comocitar\#comocitar (26-10-2013).

ONTSI (2013): XL Oleada del panel de hogares "Las TIC en los hogares españoles". Madrid. http://www.ontsi.red.es/ontsi/sites/default/files/xl_oleada_panel_hogares_2t_2013.pdf (10/01/2014).

OPORTO ORDÓÑEZ, Luis (2010): "Rendición de cuentas". Rev. Fuent. Cong. [online], $\mathrm{n}^{\mathrm{o}} 11$, vol.4, pp.4. http://www.revistasbolivianas.org.bo/pdf/fdc/v4n11/a02.pdf $(20 / 01 / 2014)$.

SÁEZ, Fernando (2013): "Conviene desarrollar una inteligencia Tecnosocial". Telos, 94, pp. 13-22. http://sociedadinformacion.fundacion.telefonica.com/DYC/TELOS 
/ResultadoBsquedaTELOS/DetalleArticuloTelos 94TELOS_AUTINV1/seccion=1227\&idioma $=$ es_ES\&id=2013021317550002 \&activo=6. $\overline{\text { do }}(24-10-2013)$.

SCHEDLER, Andreas (2008): ¿Qué es la rendición de cuentas? México, IFFAI, http://inicio.ifai.org.mx/Publicaciones/cuadernillo10.pdf (24-10-2013).

SIXTO, José (2013): “Gobiernos en la calle y ciudadanos en las redes sociales”. Telos, 94, pp. 58-67. http://sociedadinformacion.fundacion.telefonica.com/DYC/TELOS /ResultadoBsquedaTELOS/DetalleArticuloTelos_94TELOS_DOSSIER2/seccion $=1227 \&$ idioma $=$ es_ES\&id $=2013021317570002$ \&activo $=\overline{6 . d o}(24-10-2013)$.

TELLO, Lucía (2013): "Intimidad y «extimidad» en las redes sociales. Las demarcaciones éticas de Facebook". Comunicar, 41, pp. 205-213. http://dx.doi.org/10.3916 /C41-2013-20 (29-10-2013).

THE COKTAIL ANALYSIS (2013): V Oleada. Observatorio de Redes Sociales Informe Público de Resultados. http://es.slideshare.net/TCAnalysis/5-oleada-observatorio-redes-sociales (27-10-2013).

VIDELA, José Juan y PIÑEIRO, Teresa (2013): “Hacia una 'radio social'. Interacción, proyección y repercusión de las cadenas españolas en las redes sociales". Icono 14, volumen 11 (2), pp. 83-113. http://dx.doi.org/10.7195/ri14.v11i2.592 (28-102013). 